\title{
Comparative Effectiveness and Safety of Rivaroxaban and Warfarin Among Nonvalvular Atrial Fibrillation (NVAF) Patients with Obesity and Polypharmacy in the United States (US)
}

\author{
Jeffrey S. Berger · François Laliberté (D) - Akshay Kharat • \\ Dominique Lejeune (D) - Kenneth Todd Moore (D) · Young Jung • \\ Patrick Lefebvre · Veronica Ashton (D)
}

Received: March 10, 2021 / Accepted: April 13, 2021 / Published online: May 25, 2021

(c) The Author(s) 2021

\begin{abstract}
Introduction: Current evidence indicates that rivaroxaban may be a safe and effective alternative to warfarin among patients with nonvalvular atrial fibrillation (NVAF) and obesity. However, evidence regarding the impact of polypharmacy is limited in this population. The present study evaluated the effectiveness and safety of rivaroxaban versus warfarin among NVAF patients with obesity and polypharmacy in the US.

Methods: De-identified health insurance claims data from the IQVIA PharMetrics ${ }^{\circledR}$ Plus data $(01 / 2010-09 / 2019)$ were used to identify NVAF patients with obesity $\left(\mathrm{BMI} \geq 30 \mathrm{~kg} / \mathrm{m}^{2}\right)$ and
\end{abstract}

Supplementary Information The online version contains supplementary material available at https:// doi.org/10.1007/s12325-021-01746-2.

J. S. Berger

New York University School of Medecine, New York, NY 10016, USA

F. Laliberté · D. Lejeune ( $₫)$ · Y. Jung · P. Lefebvre Groupe d'analyse Ltée, Montréal, QC H3B 0G7, Canada

e-mail: Dominique.Lejeune@analysisgroup.com

A. Kharat · V. Ashton

Janssen Scientific Affairs, LLC, Titusville, NJ 08560, USA

K. T. Moore

Janssen Pharmaceuticals, Inc., Titusville, NJ 08560, USA polypharmacy ( $\geq 5$ medications) initiated on rivaroxaban or warfarin. Inverse probability of treatment weighting (IPTW) was used to adjust for imbalances between groups. Study outcomes were evaluated up to 36 months post-treatment initiation and included the composite of stroke or systemic embolism (stroke/SE) and major bleeding. Subgroup analyses were conducted stratified by polypharmacy category (5-9 or $\geq 10$ medications). Outcomes were assessed using Cox proportional hazards regression models with hazard ratios (HR) and 95\% confidence intervals (CIs).

Results: A total of 7000 and 3920 NVAF patients with obesity and polypharmacy were initiated on rivaroxaban and warfarin, respectively. At 36 months of follow-up, rivaroxaban was associated with a $29 \%$ lower risk of stroke/ SE relative to warfarin (HR 0.71, 95\% CI 0.57, 0.90). Major bleeding risk was not significantly different among rivaroxaban- compared to warfarin-treated patients (HR 0.85, 95\% CI 0.70, 1.03). Subgroup analyses yielded results that were largely consistent with the overall polypharmacy analysis.

Conclusions: These results suggest that rivaroxaban is an effective and safe treatment option among NVAF patients with obesity and polypharmacy in a commercially-insured US population. 
Keywords: Polypharmacy; Nonvalvular atrial fibrillation; Obesity; Rivaroxaban; Stroke/ systemic embolism

\section{Key Summary Points}

Current evidence indicates that rivaroxaban may be a safe and effective alternative to warfarin among patients with nonvalvular atrial fibrillation (NVAF) and obesity, although the added impact of polypharmacy in this population warrants further investigation

The present real-world study hypothesized that rivaroxaban would be an effective and safe treatment option compared to warfarin among NVAF patients with obesity and polypharmacy use ( $\geq 5$ medications)

In this retrospective study of NVAF patients with obesity and polypharmacy in the US, rivaroxaban was associated with a significantly lower risk of stroke/ systemic embolism and a similar risk of major bleeding compared to warfarin over a 36-month follow-up period

This pattern of results remained consistent in the subgroup analyses of patients with 5-9 and $\geq 10$ medications

The present findings support our initial hypothesis that rivaroxaban is a viable treatment option with long-term incremental benefits compared to warfarin among complex NVAF patients with obesity and polypharmacy in a commercially-insured US population

\section{DIGITAL FEATURES}

This article is published with digital features, including a summary slide, to facilitate understanding of the article. To view digital features for this article go to https://doi.org/10.6084/ m9.figshare.14401397.

\section{INTRODUCTION}

Obesity is a major risk factor for developing atrial fibrillation (AF) $[1,2]$, which in turn confers an elevated risk of stroke and systemic embolism (SE) [3, 4]. Although AF is predominantly a disease of the elderly (mean age $\geq 70$ years) [5-8], obesity has been associated with a higher risk of incident $\mathrm{AF}$ in younger individuals [9-13], even in the absence of additional predisposing risk factors [11]. Nonvalvular AF (NVAF) is the most common type of AF in the US, accounting for $>15 \%$ of all strokes [14]. Direct-acting oral anticoagulants (DOAC) [15-17] such as rivaroxaban are being increasingly preferred over vitamin $\mathrm{K}$ antagonists (VKA) such as warfarin for the treatment of NVAF $[18,19]$ because of their limited drug and food interactions without the need for routine laboratory monitoring and dosage adjustments $[20,21]$. Current evidence indicates that the pharmacokinetic profile of rivaroxaban is not significantly impacted by body weight [22-24]. Rivaroxaban may also be considered a safe and effective alternative to warfarin among NVAF patients with obesity based on analyses of clinical trial data [25-27] and the findings of recent observational studies [28-32].

Despite this accumulating evidence that rivaroxaban is safe and effective among NVAF patients with obesity [25-32], the added impact of polypharmacy use among this population warrants further investigation. Polypharmacy, commonly defined as the concurrent use of $\geq 5$ medications [33-35], has become increasingly prevalent in the US [36]. In particular, NVAF is associated with multiple comorbidities requiring concomitant medication use, resulting in an estimated polypharmacy rate of $>50 \%$ [37]. Obesity is also associated with frequent complications and comorbidities, which is likely to contribute to increasing dependence on polypharmacy $[36,38,39]$. Polypharmacy is linked to poor clinical outcomes and reduced anticoagulation control, which may reflect drug-drug interactions and the negative impact 
of multiple medication use on adherence [34, 40-44]. Warfarin-treated patients with polypharmacy may be especially prone to drugdrug interactions, which are associated with increased risk of bleeding complications $[42,45]$

To date, several studies have examined the impact of polypharmacy on the performance of anticoagulants such as rivaroxaban and warfarin among patients irrespective of body weight or body mass index (BMI) [37, 44, 46]. These prior studies suggest that rivaroxaban is safe and effective across complex patients with polypharmacy. In an analysis of the ROCKET AF trial population, Piccini et al. [44] examined the risk of stroke and bleeding events between rivaroxaban and warfarin according to number of concurrent baseline medications (i.e., 0-4, $5-9$, and $\geq 10$ ). Overall, there was no difference in outcomes between rivaroxaban and warfarintreated patients with increasing number of medications. In more recent retrospective claims-based studies of polypharmacy users, rivaroxaban has been associated with a risk of stroke/SE that is similar or reduced compared to warfarin, with no difference in the risk of major bleeding [37, 46].

Studies investigating the impact of polypharmacy on the clinical outcomes among anticoagulant users with obesity are currently scarce in the literature. To address this knowledge gap, the present study compared the effectiveness and safety of rivaroxaban and warfarin in a nationally representative commercially-insured population of NVAF patients with obesity and polypharmacy in the US. We hypothesized that rivaroxaban would be an effective and safe treatment option for NVAF patients with obesity and polypharmacy compared to warfarin.

\section{METHODS}

\section{Data Source}

The IQVIA PharMetrics ${ }^{\circledR}$ Plus data spanning from January 1, 2010, to September 30, 2019, were used to meet the study objectives. The IQVIA PharMetrics ${ }^{\circledR}$ Plus data used for the study offered a diverse representation of enrollees and are representative across geographic zones in the US. They contained around 40 million patients with both medical and pharmacy benefits in any given recent year, with an average length of health plan enrollment of approximately 39 months. The enrollee population in the IQVIA PharMetrics ${ }^{\circledR}$ Plus data is generally representative of the $<65$ years of age, commercially-insured population in the US with respect to both age and gender. All database records were statistically de-identified and certified as fully compliant with US patient confidentiality requirements outlined in the Health Insurance Portability and Accountability Act. Permission to access these records for the current study was granted by IQVIA PharMetrics ${ }^{\circledR}$ Plus data. Because the current study relied exclusively on de-identified patient records and did not involve the collection, use, or dissemination of individually identifiable data, institutional review board approval was not necessary.

\section{Study Design and Population}

A retrospective weighted-cohort design was used to evaluate outcomes among NVAF patients with obesity and polypharmacy initiated on rivaroxaban or warfarin. Eligible patients were those with $\geq 1$ dispensing for rivaroxaban or warfarin between November 4, 2011, and September 30, 2019 (identification period), with the first dispensing defined as the index date. The baseline period was defined as the 12 months prior to the index date. Although rivaroxaban was approved in November 2011, only patients with an index date on or after January 1, 2013, were included in the study population as it may take a certain amount of time for recently approved medications to be prescribed and early adopters may differ in their characteristics. Patients in the overall polypharmacy cohort were defined as having $\geq 5$ concurrent outpatient pharmacy dispensings for any medications on the index date (including rivaroxaban or warfarin); concurrent use was defined based on the number of dispensing with days of supplies overlapping 
with the index date [34]. At the index date, patients in the overall polypharmacy cohort were further stratified based on categories used in the analysis of the ROCKET AF trial population by Piccini et al. [44], with patients having either 5-9 medications or $\geq 10$ medications.

Patients were required to meet the following additional inclusion criteria: $\geq 1$ medical claim with a diagnosis of AF (International Classification of Diseases, Ninth Revision, Clinical Modification [ICD-9-CM]: 427.31 or International Classification of Diseases, Tenth Revision, Clinical Modification [ICD-10-CM]: I48.0-148.2x, 148.91) during the baseline period or on the index date, $\geq 1$ medical claim with a diagnosis code for obesity or BMI $\geq 30 \mathrm{~kg} / \mathrm{m}^{2}$ (see Table S1 for a list of ICD-9$\mathrm{CM}$ and ICD-10-CM codes used to define obesity/BMI $\geq 30 \mathrm{~kg} / \mathrm{m}^{2}$ ) during the baseline period or on the index date, $\geq 12$ months of continuous health plan enrollment before the index date (i.e., baseline period), and $\geq 18$ years of age in the index year. A prior study has validated the use of diagnosis codes for identifying obesity among NVAF patients with high positive predictive value (PPV; 89.8\%) and high specificity (95.2\%) [47]. Patients were excluded from the analysis if they had pharmacy claims for $>1$ oral anticoagulant (i.e., rivaroxaban, warfarin, apixaban, edoxaban, betrixaban, or dabigatran) at the index date or if they met any of the following exclusion criteria during the baseline period: $\geq 1$ pharmacy claim for an oral anticoagulant, $\geq 1$ medical claim for VTE or knee or hip replacement surgery, $\geq 1$ medical claim with a diagnosis of mitral-stenosis, or $\geq 1$ medical claim for a mechanical heart valve procedure.

Patients' demographics and clinical characteristics were evaluated during the baseline period and outcomes were evaluated at followup. Clinical effectiveness outcomes were assessed using an intention-to-treatment (ITT) approach, which spanned from the index date until the earliest of 36 months, health plan disenrollment, or end of data availability. The safety outcome was assessed using an on-treatment approach that was censored upon the earliest date of switch to or addition of another anticoagulant (so that patients were continuously treated with the index anticoagulant), anticoagulant discontinuation, 36 months, health plan disenrollment, or end of data availability. Anticoagulant discontinuation was defined as a gap of $\geq 60$ days of supply between the end of an anticoagulant dispensing and the next medication refill or end of data availability. In a sensitivity analysis, outcomes were also assessed using an on-treatment approach.

\section{Study Outcomes}

Effectiveness and safety outcomes were assessed over a 36-month follow-up period. The primary effectiveness outcome was the composite of stroke (ischemic or hemorrhagic) or SE (stroke/ $\mathrm{SE}$ ), which was defined as a primary diagnosis of stroke or SE documented in a hospitalization or emergency room visit (see Table S2 for the list of diagnosis codes used to identify stroke/SE). The effectiveness outcomes were also assessed separately (i.e., stroke, ischemic stroke, hemorrhagic stroke, and SE). The safety outcome was the occurrence of a major bleeding event, which was identified using hospitalizations with diagnoses and procedures indicating an episode of bleeding (i.e., Cunningham algorithm) [48]. Of note, hemorrhagic stroke was also included in the definition of a major bleeding event.

\section{Statistical Analysis}

Inverse probability of treatment weighting (IPTW) based on the propensity score (PS) was used to balance the rivaroxaban and warfarin cohorts, with PS defined as the conditional probability of receiving rivaroxaban based on observable covariates [49]. The IPTW approach uses weights derived from the PS to create a pseudo-population, so that the distribution of covariates in the population is independent of treatment assignment. Patients' weight in each cohort was equal to the inverse of their probability of receiving treatment with rivaroxaban (i.e., 1/PS for the rivaroxaban cohort and $1 /[1-\mathrm{PS}]$ for the warfarin cohort). Variables used in the PS calculation included age, sex, year of index date, region, type of insurance 
plan, obesity type, baseline stroke/SE, baseline major bleeding, cardiovascular-related medications, cardiovascular procedures, use of nonoral anticoagulants, prior history of cancer diagnosis and cancer treatment, baseline HRU and healthcare costs, and baseline risk factors for stroke and bleeding events (with $\geq 5 \%$ prevalence in either cohorts).

Patient characteristics by treatment cohort were evaluated using descriptive statistics including mean, standard deviation (SD), and median values for the continuous variables and relative frequencies and proportions for the categorical variables. Differences in baseline characteristics between patients in the cohorts were assessed using standardized differences. A standardized difference $<10 \%$ was considered a negligible imbalance [50].

Time to stroke/SE and time to major bleeding events were assessed with weighted KaplanMeier (KM) survival analysis. Cumulative KM rates were reported at 12,24 , and 36 months following the index date. Study outcomes were also assessed and compared between cohorts using weighted Cox proportional hazards regression models, with corresponding hazard ratios (HR), 95\% confidence intervals (CI), and $p$ values.

\section{RESULTS}

NVAF patients with obesity and polypharmacy included a total of 7000 patients initiated on rivaroxaban and 3920 patients initiated on warfarin. The subgroup with 5-9 medications comprised 5339 rivaroxaban-treated patients and 2574 warfarin-treated patients and the subgroup with $\geq 10$ comprised 1661 rivaroxaban-treated patients and 1346 warfarin-treated patients (Fig. 1).

\section{Baseline Demographics and Clinical Characteristics}

Among the overall polypharmacy cohort, the weighted rivaroxaban and warfarin cohorts were well balanced (i.e., std. diff. $<10 \%$ ) with respect to baseline demographic and clinical characteristics (Table 1) and baseline comorbidities (Table 2). In the rivaroxaban and warfarin cohorts, the mean age was 60 years, $31 \%$ of the patients were female. Patients in the weighted rivaroxaban and warfarin cohorts had comparable values for the Quan-Charlson comorbidity index (CCI) score (mean: 2.06 and 2.02, respectively), $\mathrm{CHA}_{2} \mathrm{DS}_{2}$-VASc score (mean: 2.96 and 3.00, respectively), and HAS-BLED score (mean: 1.99 and 1.98, respectively; Table 2). In the rivaroxaban cohort, $90 \%$ of patients had dispensings for the label standard dose of $20 \mathrm{mg}$ for NVAF. Among the 15 most frequently dispensed drug classes at the index date in NVAF patients with obesity and polypharmacy ( $\geq 5$ medications), those with the highest proportion of dispensing were betablockers, antihypertensives, and antihyperlipidemics (Table S3). For polypharmacy patients with 5-9 and $\geq 10$ medications, the weighted rivaroxaban and warfarin cohorts were well balanced with respect to baseline characteristics and comorbidities (i.e., std. diff. $<10 \%$; see Table S4 and Table S5).

\section{Risk of Stroke and Systemic Embolism}

In the overall polypharmacy cohort, patients treated with rivaroxaban had a significantly lower risk of stroke/SE at all time points postindex (Fig. 2). At 36 months of follow-up, rivaroxaban was associated with a $29 \%$ lower risk of stroke/SE compared to warfarin (HR 0.71, 95\% CI 0.57, 0.90, $p=0.004$; Fig. 2). Moreover, the risk of stroke (i.e., ischemic stroke and hemorrhagic stroke) and hemorrhagic stroke were significantly lower with rivaroxaban compared to warfarin at all time points post-index (Table S6). The risk of ischemic stroke was significantly lower with rivaroxaban compared to warfarin at 24 months of follow-up (HR 0.75, 95\% CI 0.57, 0.99, $p=0.044$; Table S6).

Results of an on-treatment sensitivity analysis were consistent with the ITT findings. In particular, patients treated with rivaroxaban had a significantly lower risk of stroke/SE compared to those treated with warfarin at 12 months (HR 0.58, 95\% CI 0.42, 0.80, $p<0.001$ ), 24 months (HR 0.59, 95\% CI 0.44, 


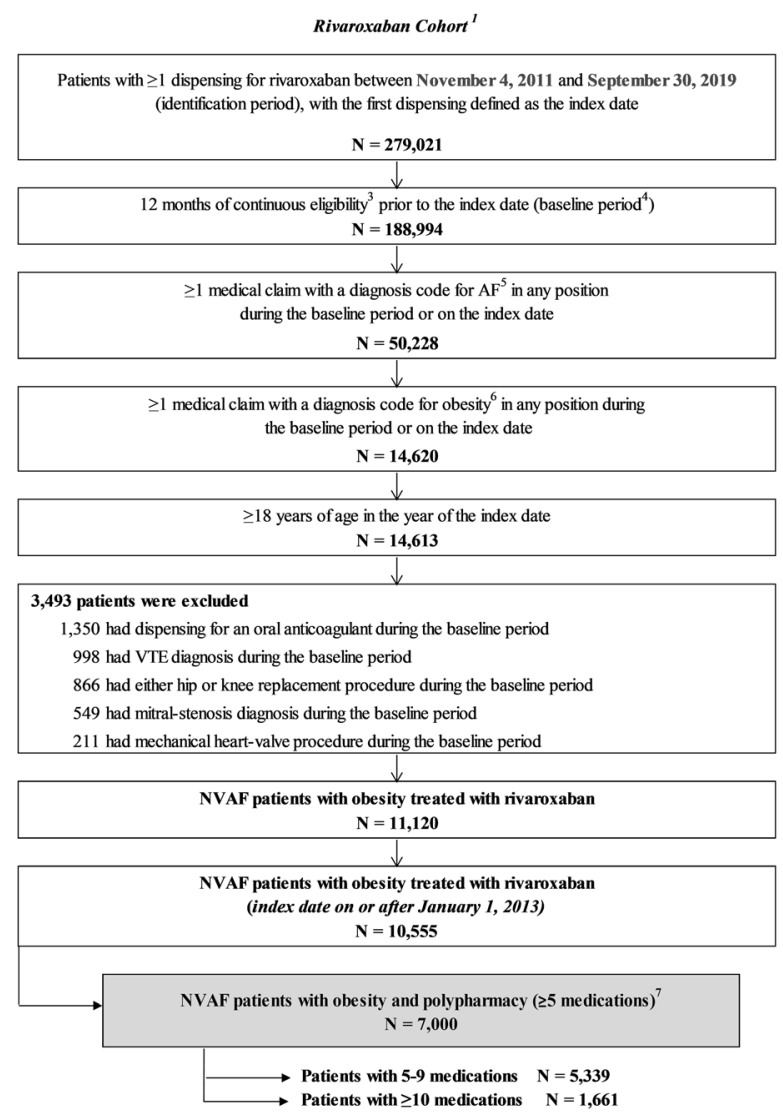

Fig. 1 Patient disposition: NVAF polypharmacy population. Data Source: IQVIA PharMetrics ${ }^{\circledR}$ Plus data, consisting of AF patients with obesity, from January 1, 2010, to September 30, 2019. $A F$ atrial fibrillation, $B M I$ body mass index, GPI generic product identifier, $I C D$ International Classification of Disease, $N V A F$ nonvalvular atrial fibrillation, VTE venous thromboembolism. Notes: (1) A total of 326 rivaroxaban patients with $>1$ oral anticoagulant medication on the index date were excluded. (2) A total of 379 warfarin patients with $>1$ oral anticoagulant medication on the index date were excluded.

$0.80, p<0.001$ ), and 36 months (HR: $0.63,95 \%$ CI $0.48,0.84, p=0.002$ ).

\section{Risk of Major Bleeding}

In the overall polypharmacy cohort, risk of major bleeding was numerically but not significantly lower among rivaroxaban- compared to warfarin-treated patients at 36 months of follow-up (HR 0.85, 95\% CI 0.70, 1.03, $p=0.089$; Fig. 3). Similarly, there was no significant

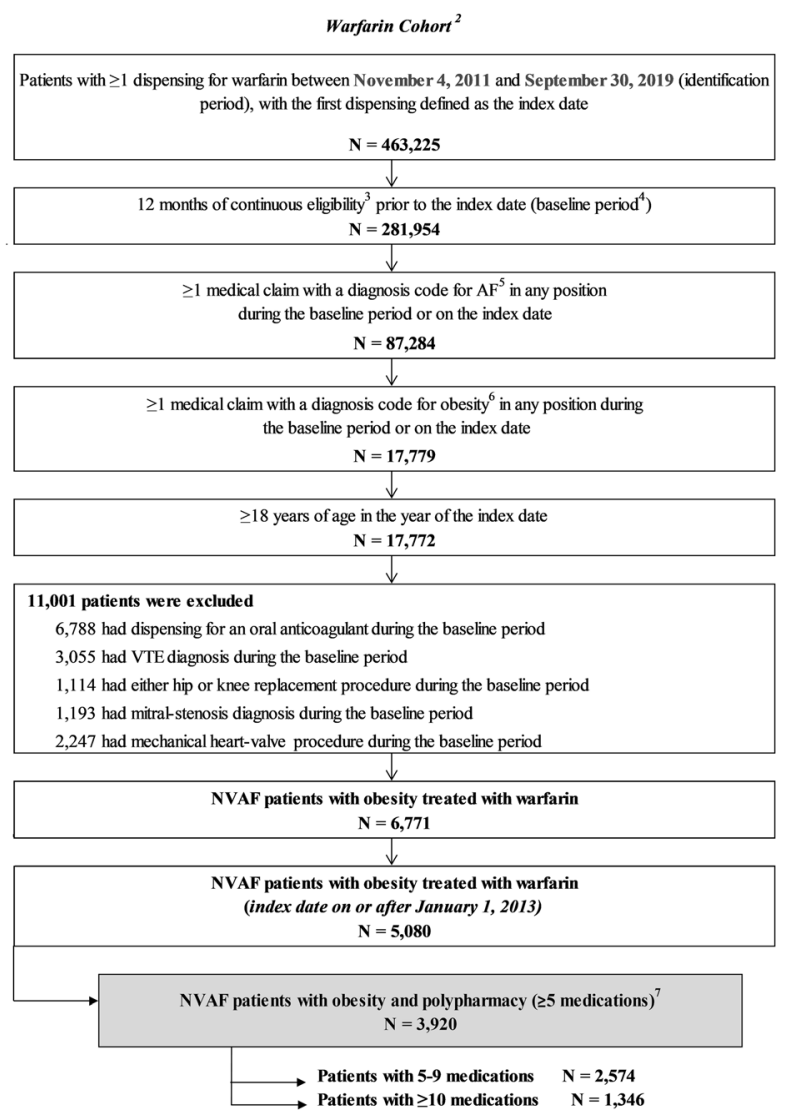

(3) Continuous eligibility was defined as continuous health plan enrollment with medical and pharmacy coverage. (4) Baseline period was defined as the 12 months prior to the index date. (5) AF was identified with the following ICD9-CM: 427.31 and ICD-10-CM: I48.0-148.2x, 148.91. (6) See Table S1 for obesity diagnosis codes. (7) Patients with concurrent pharmacy dispensing for $\geq 5$ different medications based on the date of the pharmacy claim and days' supply on the index date. Chen et al. [34]

difference in the risk of major bleeding among rivaroxaban- compared to warfarin-treated patients at 12 months (HR 0.95, 95\% CI 0.76, $1.18, p=0.623$ ) and 24 months (HR 0.89, 95\% CI $0.73,1.03, p=0.259$ ).

\section{Polypharmacy with 5-9 Medications and $10+$ Medications}

In the subgroup analysis of patients with 5-9 medications, rivaroxaban was associated with a 
Table 1 Baseline demographic and clinical characteristics of NVAF patients with obesity and polypharmacy ( $\geq 5$ medications)-rivaroxaban and warfarin cohorts

\begin{tabular}{|c|c|c|c|c|c|c|}
\hline \multirow[t]{2}{*}{ Characteristics } & \multicolumn{3}{|c|}{ Unweighted cohorts } & \multicolumn{3}{|l|}{ Weighted cohorts $^{a}$} \\
\hline & $\begin{array}{l}\text { Rivaroxaban } \\
N=7000\end{array}$ & $\begin{array}{l}\text { Warfarin } \\
N=3920\end{array}$ & $\begin{array}{l}\text { Std. } \\
\text { diff. }^{\text {b,c }} \\
(\%)\end{array}$ & $\begin{array}{l}\text { Rivaroxaban } \\
N=7000\end{array}$ & $\begin{array}{l}\text { Warfarin } \\
N=3920\end{array}$ & $\begin{array}{l}\text { Std. } \\
\text { diff., } \\
(\%)\end{array}$ \\
\hline $\begin{array}{l}\text { Observation } \\
\text { period, }{ }^{\mathrm{d}} \text { months, } \\
\text { mean } \pm \mathrm{SD}[\text { median }]\end{array}$ & $19.7 \pm 12.8[18]$ & $19.9 \pm 13.1[18]$ & & $20.3 \pm 12.9[19]$ & $19.5 \pm 12.9[18]$ & \\
\hline \multicolumn{7}{|l|}{ Demographics $^{\mathrm{e}}$} \\
\hline $\begin{array}{l}\text { Age, years, } \\
\text { mean } \pm \mathrm{SD}[\text { median }]\end{array}$ & $59.5 \pm 8.1[60]$ & $61.3 \pm 8.6[62]$ & 21.9 & $60.2 \pm 8.1[61]$ & $60.1 \pm 8.6[61]$ & 0.6 \\
\hline$\geq 65$ years & $1369(19.6)$ & $1091(27.8)$ & 19.5 & $1545(22.1)$ & $909(23.2)$ & 2.7 \\
\hline Sex, female, $n(\%)$ & $2208(31.5)$ & $1224(31.2)$ & 0.7 & $2174(31.1)$ & $1262(32.2)$ & 2.5 \\
\hline \multicolumn{7}{|l|}{ Region, ${ }^{\mathrm{e}} n(\%)$} \\
\hline South & $1615(23.1)$ & $1112(28.4)$ & 12.1 & $1721(24.6)$ & $944(24.1)$ & 1.2 \\
\hline Midwest & $1922(27.5)$ & $1258(32.1)$ & 10.1 & $2042(29.2)$ & $1153(29.4)$ & 0.5 \\
\hline Northeast & $2921(41.7)$ & $1,097(28.0)$ & 28.8 & $2584(36.9)$ & $1477(37.7)$ & 1.6 \\
\hline West & $542(7.7)$ & $453(11.6)$ & 12.9 & $653(9.3)$ & $346(8.8)$ & 1.7 \\
\hline \multicolumn{7}{|l|}{ Insurance plan type, ${ }^{\mathrm{e}} n(\%)$} \\
\hline $\mathrm{PPO}$ & $5990(85.6)$ & $3223(82.2)$ & 9.1 & $5867(83.8)$ & $3295(84.1)$ & 0.7 \\
\hline HMO & $577(8.2)$ & $361(9.2)$ & 3.4 & $633(9.0)$ & $333(8.5)$ & 1.9 \\
\hline POS & $244(3.5)$ & $139(3.5)$ & 0.3 & $241(3.4)$ & $140(3.6)$ & 0.7 \\
\hline Indemnity/traditional & $161(2.3)$ & $177(4.5)$ & 12.2 & $228(3.3)$ & $133(3.4)$ & 0.7 \\
\hline Unknown & $23(0.3)$ & $15(0.4)$ & 0.9 & $26(0.4)$ & $16(0.4)$ & 0.4 \\
\hline $\mathrm{CDHC}$ & $5(0.1)$ & $3(0.1)$ & 0.2 & $6(0.1)$ & $3(0.1)$ & 0.2 \\
\hline \multicolumn{7}{|l|}{ Insurance payer type, ${ }^{\text {e,f }} n(\%)$} \\
\hline Commercial & $3825(54.6)$ & $2097(53.5)$ & 2.3 & $3841(54.9)$ & $2143(54.7)$ & 0.4 \\
\hline Self-insured & $2986(42.7)$ & $1610(41.1)$ & 3.2 & $2935(41.9)$ & $1613(41.1)$ & 1.6 \\
\hline Medicare Advantage & $129(1.8)$ & $178(4.5)$ & 15.3 & $154(2.2)$ & $131(3.3)$ & 6.9 \\
\hline Medicaid & $37(0.5)$ & $20(0.5)$ & 0.3 & $44(0.6)$ & $18(0.5)$ & 2.2 \\
\hline Unknown & $23(0.3)$ & $15(0.4)$ & 0.9 & $26(0.4)$ & $16(0.4)$ & 0.4 \\
\hline $\begin{array}{l}\text { Morbid obesity }(\mathrm{BMI} \geq 40)^{g} \\
n(\%)\end{array}$ & $2708(38.7)$ & $1672(42.7)$ & 8.1 & $2798(40.0)$ & $1621(41.4)$ & 2.8 \\
\hline \multicolumn{7}{|c|}{ Baseline stroke/SE and major bleeding, ${ }^{\mathrm{h}} n(\%)$} \\
\hline Stroke/SE & $243(3.5)$ & $343(8.8)$ & 22.0 & $441(6.3)$ & $220(5.6)$ & 2.9 \\
\hline Ischemic stroke & $224(3.2)$ & $311(7.9)$ & 20.6 & $387(5.5)$ & $203(5.2)$ & 1.6 \\
\hline Hemorrhagic stroke & $12(0.2)$ & $36(0.9)$ & 10.1 & $38(0.5)$ & $21(0.5)$ & 0.1 \\
\hline
\end{tabular}


Table 1 continued

\begin{tabular}{|c|c|c|c|c|c|c|}
\hline \multirow[t]{2}{*}{ Characteristics } & \multicolumn{3}{|c|}{ Unweighted cohorts } & \multicolumn{3}{|c|}{ Weighted cohorts $^{\mathrm{a}}$} \\
\hline & $\begin{array}{l}\text { Rivaroxaban } \\
N=7000\end{array}$ & $\begin{array}{l}\text { Warfarin } \\
N=3920\end{array}$ & $\begin{array}{l}\text { Std. } \\
\text { diff. } \\
(\%)\end{array}$ & $\begin{array}{l}\text { Rivaroxaban } \\
N=7000\end{array}$ & $\begin{array}{l}\text { Warfarin } \\
N=3920\end{array}$ & $\begin{array}{l}\text { Std. } \\
\text { diff. }^{\text {b,c }} \\
(\%)\end{array}$ \\
\hline SE & $16(0.2)$ & $29(0.7)$ & 7.4 & $29(0.4)$ & $15(0.4)$ & 0.6 \\
\hline Major bleeding & $138(2.0)$ & $210(5.4)$ & 18.0 & $287(4.1)$ & $128(3.3)$ & 4.3 \\
\hline Gastric bypass surgery, ${ }^{\mathrm{h}} n(\%)$ & $40(0.6)$ & $29(0.7)$ & 2.1 & $37(0.5)$ & $26(0.7)$ & 1.8 \\
\hline \multicolumn{7}{|l|}{ Polypharmacy category, ${ }^{\mathrm{e}, \mathrm{i}} n(\%)$} \\
\hline Dispensings for $\geq 10$ medications & $1661(23.7)$ & $1346(34.3)$ & 23.4 & $1881(26.9)$ & $1125(28.7)$ & 4.1 \\
\hline $\begin{array}{l}\text { Dispensing of non-oral } \\
\text { anticoagulants, }{ }^{\mathrm{h}} n(\%)\end{array}$ & $1106(15.8)$ & $767(19.6)$ & 9.9 & $1201(17.2)$ & $670(17.1)$ & 0.2 \\
\hline $\begin{array}{l}\text { Dispensing of cardiovascular-related } \\
\text { medications, }{ }^{\mathrm{h}} n(\%)\end{array}$ & $6387(91.2)$ & $3535(90.2)$ & 3.7 & $6361(90.9)$ & $3565(90.9)$ & 0.3 \\
\hline Antihypertensive agents & $5931(84.7)$ & $3313(84.5)$ & 0.6 & $5945(84.9)$ & $3319(84.7)$ & 0.8 \\
\hline Antihyperlipidemic agents & $4168(59.5)$ & $2431(62.0)$ & 5.1 & $4280(61.1)$ & $2352(60.0)$ & 2.3 \\
\hline Antiplatelet agents & $735(10.5)$ & $554(14.1)$ & 11.1 & $963(13.8)$ & $447(11.4)$ & 7.2 \\
\hline Cardiovascular procedures, ${ }^{\mathrm{h}} n(\%)$ & $414(5.9)$ & $654(16.7)$ & 34.0 & $749(10.7)$ & $395(10.1)$ & 2.1 \\
\hline $\begin{array}{l}\text { Percutaneous coronary } \\
\text { intervention }\end{array}$ & $268(3.8)$ & $281(7.2)$ & 14.7 & $444(6.3)$ & $175(4.5)$ & 8.4 \\
\hline Coronary bypass graft & $169(2.4)$ & $410(10.5)$ & 32.8 & $353(5.0)$ & $240(6.1)$ & 4.7 \\
\hline $\begin{array}{l}\text { Prior history of cancer diagnosis/ } \\
\text { treatment, }{ }^{\mathrm{h}} n(\%)\end{array}$ & $932(13.3)$ & $594(15.2)$ & 5.3 & $1014(14.5)$ & $538(13.7)$ & 2.2 \\
\hline
\end{tabular}

$B M I$ body mass index, $C D H C$ consumer-directed health care, $H M O$ health maintenance organization, $N V A F$ nonvalvular atrial fibrillation, POS point of service, PPO preferred provider organization, SD standard deviation, SE systemic embolism, Std. diff. standard difference

${ }^{a}$ Rivaroxaban and warfarin patients were weighted using the inverse probability of treatment weighting approach based on the propensity score

b For continuous variables, the standardized difference is calculated by dividing the absolute difference in means of the control and the case by the pooled standard deviation of both groups. The pooled standard deviation is the square root of the average of the squared standard deviations

c For dichotomous variables, the standardized difference is calculated using the following equation where $\mathrm{P}$ is the respective proportion of participants in each group: $\left.\left|\left(P_{\text {case }}-P_{\text {control }}\right)\right| / \sqrt{ }\left[\left(P_{\text {case }} 1-P_{\text {case }}\right)+P_{\text {control }}\left(1-P_{\text {control }}\right)\right) / 2\right]$

d Observation period spans from the index date to the earliest of: 36 months, end of continuous enrollment, or end of data availability

e Evaluated at the index date

${ }^{f}$ Self-insured should be considered together with Commercial to represent total commercially-insured patients

$\mathrm{g}$ Based on the closest value to the index date, evaluated during the 12 months prior to the index date, including the index date

h Evaluated during the 12 months prior to the index date, excluding the index date

${ }^{\mathrm{i}}$ Polypharmacy is defined as pharmacy dispensing for different medications (first 8 digits of GPI) on the index date [44] 
Table 2 Baseline comorbidities of NVAF patients with obesity and polypharmacy ( $\geq 5$ medications) -rivaroxaban and warfarin cohorts

\begin{tabular}{|c|c|c|c|c|c|c|}
\hline \multirow[t]{2}{*}{ Clinical characteristics $^{\mathbf{a}}$} & \multicolumn{3}{|c|}{ Unweighted cohorts } & \multicolumn{3}{|c|}{ Weighted cohorts ${ }^{b}$} \\
\hline & $\begin{array}{l}\text { Rivaroxaban } \\
N=7000\end{array}$ & $\begin{array}{l}\text { Warfarin } \\
N=3920\end{array}$ & $\begin{array}{l}\text { Std. } \\
\text { diff. } \\
(\%)\end{array}$ & $\begin{array}{l}\text { Rivaroxaban } \\
N=7000\end{array}$ & $\begin{array}{l}\text { Warfarin } \\
N=3920\end{array}$ & $\begin{array}{l}\text { Std. } \\
\text { diff. }^{c, d} \\
(\%)\end{array}$ \\
\hline $\begin{array}{l}\text { Quan-CCI, } \\
\text { mean } \pm \text { SD [median] }\end{array}$ & $1.71 \pm 1.84[1]$ & $2.47 \pm 2.13[2]$ & 38.1 & $2.06 \pm 2.19[2]$ & $2.02 \pm 2.00[2]$ & 2.1 \\
\hline $\begin{array}{l}\mathrm{CHA}_{2} \mathrm{DS}_{2} \text {-VASc score, } \\
\text { mean } \pm \mathrm{SD}[\text { median }]\end{array}$ & $2.67 \pm 1.41[2]$ & $3.42 \pm 1.59[3]$ & 49.8 & $2.96 \pm 1.55[3]$ & $3.00 \pm 1.50[3]$ & 2.8 \\
\hline $\begin{array}{l}\text { HAS-BLED score, mean } \pm \text { SD } \\
{[\text { median }]}\end{array}$ & $1.86 \pm 0.99[2]$ & $2.14 \pm 1.13[2]$ & 26.6 & $1.99 \pm 1.09[2]$ & $1.98 \pm 1.06[2]$ & 0.7 \\
\hline \multicolumn{7}{|c|}{ Risk factors for stroke and bleeding events, $n(\%)$} \\
\hline Hypertension & $6420(91.7)$ & $3636(92.8)$ & 3.9 & $6460(92.3)$ & $3632(92.7)$ & 1.4 \\
\hline Arrhythmia (excluding AF) & $6234(89.1)$ & $3599(91.8)$ & 9.4 & $6307(90.1)$ & $3523(89.9)$ & 0.7 \\
\hline Hyperlipidemia & $5145(73.5)$ & $2951(75.3)$ & 4.1 & $5200(74.3)$ & $2904(74.1)$ & 0.5 \\
\hline Diabetes & $3319(47.4)$ & $2272(58.0)$ & 21.1 & $3597(51.4)$ & $2051(52.3)$ & 1.9 \\
\hline CAD & $2359(33.7)$ & $1912(48.8)$ & 30.6 & $2771(39.6)$ & $1549(39.5)$ & 0.2 \\
\hline Congestive heart failure & $2305(32.9)$ & $1917(48.9)$ & 32.5 & $2781(39.7)$ & $1543(39.4)$ & 0.7 \\
\hline NSAID use & $2021(28.9)$ & $864(22.0)$ & 15.7 & $1855(26.5)$ & $1067(27.2)$ & 1.7 \\
\hline Renal disease & $1637(23.4)$ & $1591(40.6)$ & 36.9 & $2091(29.9)$ & $1170(29.8)$ & 0.1 \\
\hline $\begin{array}{l}\text { Excessive fall risk (Parkinson's } \\
\text { disease, etc.) }\end{array}$ & $1621(23.2)$ & $938(23.9)$ & 1.8 & $1671(23.9)$ & $941(24.0)$ & 0.3 \\
\hline Chronic kidney disease & $1474(21.1)$ & $1322(33.7)$ & 28.4 & $1783(25.5)$ & $994(25.4)$ & 0.2 \\
\hline Depression & $1111(15.9)$ & $693(17.7)$ & 4.8 & $1197(17.1)$ & $651(16.6)$ & 1.3 \\
\hline Anemia & $1065(15.2)$ & $1173(29.9)$ & 35.2 & $1481(21.2)$ & $811(20.7)$ & 1.1 \\
\hline Ethanol abuse & $871(12.4)$ & $406(10.4)$ & 6.6 & $827(11.8)$ & $470(12.0)$ & 0.5 \\
\hline Myocardial infarction & $819(11.7)$ & $801(20.4)$ & 23.8 & $1090(15.6)$ & $602(15.3)$ & 0.6 \\
\hline Previous bleeding & $805(11.5)$ & $695(17.7)$ & 17.6 & $998(14.3)$ & $541(13.8)$ & 1.3 \\
\hline COPD & $798(11.4)$ & $523(13.3)$ & 5.9 & $850(12.1)$ & $485(12.4)$ & 0.7 \\
\hline Hepatic disease & $651(9.3)$ & $399(10.2)$ & 3.0 & $724(10.3)$ & $378(9.6)$ & 2.4 \\
\hline Family history of CVD & $571(8.2)$ & $272(6.9)$ & 4.6 & $551(7.9)$ & $304(7.8)$ & 0.4 \\
\hline PAD & $490(7.0)$ & $488(12.4)$ & 18.4 & $660(9.4)$ & $352(9.0)$ & 1.5 \\
\hline Left ventricular dysfunction & $271(3.9)$ & $243(6.2)$ & 10.6 & $319(4.6)$ & $181(4.6)$ & 0.3 \\
\hline Transient ischemic attack & $231(3.3)$ & $188(4.8)$ & 7.6 & $322(4.6)$ & $156(4.0)$ & 3.1 \\
\hline $\begin{array}{l}\text { Thrombocytopenia (low platelet } \\
\text { count) }\end{array}$ & $208(3.0)$ & $254(6.5)$ & 16.5 & $346(4.9)$ & $167(4.3)$ & 3.2 \\
\hline
\end{tabular}


Table 2 continued

\begin{tabular}{|c|c|c|c|c|c|c|}
\hline \multirow[t]{2}{*}{ Clinical characteristics $^{a}$} & \multicolumn{3}{|c|}{ Unweighted cohorts } & \multicolumn{3}{|c|}{ Weighted cohorts ${ }^{b}$} \\
\hline & $\begin{array}{l}\text { Rivaroxaban } \\
N=7000\end{array}$ & $\begin{array}{l}\text { Warfarin } \\
N=3920\end{array}$ & $\begin{array}{l}\text { Std. } \\
\text { diff., } \\
\text { (\%) }\end{array}$ & $\begin{array}{l}\text { Rivaroxaban } \\
N=7000\end{array}$ & $\begin{array}{l}\text { Warfarin } \\
N=3920\end{array}$ & $\begin{array}{l}\text { Std. } \\
\text { diff., } \\
\text { (\%) }\end{array}$ \\
\hline Central venous catheter & $182(2.6)$ & $464(11.8)$ & 35.7 & $508(7.3)$ & $245(6.2)$ & 4.0 \\
\hline Peptic ulcer & $116(1.7)$ & $74(1.9)$ & 1.7 & $153(2.2)$ & $58(1.5)$ & 5.2 \\
\hline Coagulation defect & $53(0.8)$ & $195(5.0)$ & 25.3 & $153(2.2)$ & $88(2.2)$ & 0.3 \\
\hline Diathesis & $3(0.0)$ & $3(0.1)$ & 1.4 & $6(0.1)$ & $3(0.1)$ & 0.9 \\
\hline
\end{tabular}

$A F$ atrial fibrillation, $C A D$ coronary artery disease, COPD chronic obstructive pulmonary disease, $C V D$ cardiovascular disease, $N V A F$ nonvalvular atrial fibrillation, NSAID nonsteroidal anti-inflammatory drugs, PAD peripheral artery disease, $S D$ standard deviation, Std. diff. standard difference, Quan-CCI Quan-Charlson comorbidity index

a Evaluated during the 12 months prior to the index date, excluding the index date

b Rivaroxaban and warfarin patients were weighted using the inverse probability of treatment weighting approach based on the propensity score

${ }^{c}$ For continuous variables, the standardized difference is calculated by dividing the absolute difference in means of the control and the case by the pooled standard deviation of both groups. The pooled standard deviation is the square root of the average of the squared standard deviations

${ }^{\mathrm{d}}$ For dichotomous variables, the standardized difference is calculated using the following equation where $\mathrm{P}$ is the respective proportion of participants in each group: $\left|\left(P_{\text {case }}-P_{\text {control }}\right)\right| / \sqrt{ }\left[\left(P_{\text {case }}\left(1-P_{\text {case }}\right)+P_{\text {control }}\left(1-P_{\text {control }}\right)\right) / 2\right]$

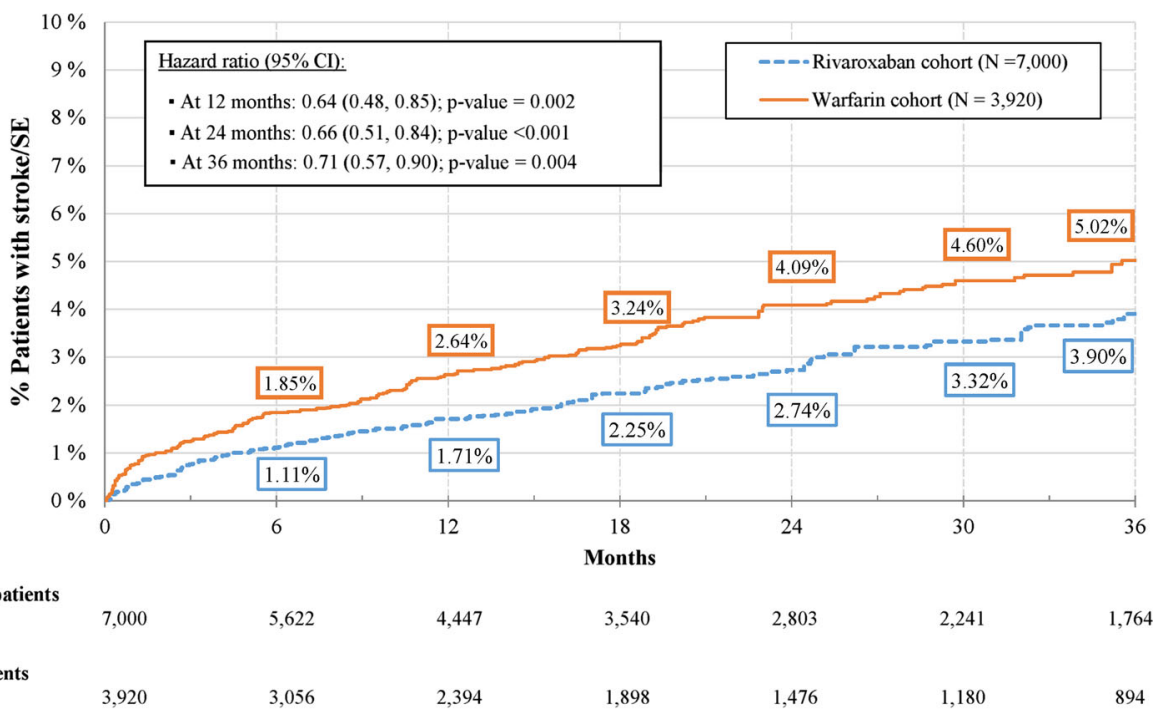

Fig. 2 Kaplan-Meier rates of stroke/SE ${ }^{1}$ : NVAF patients with obesity and polypharmacy ( $\geq 5$ medications)rivaroxaban vs. warfarin (intention-to-treat analysis). CI confidence interval, SE systemic embolism. Notes: (1)
Defined as a primary diagnosis of ischemic stroke, hemorrhagic stroke, or SE during a hospitalization or emergency. (2) Number of patients still observed at the specific point in time 


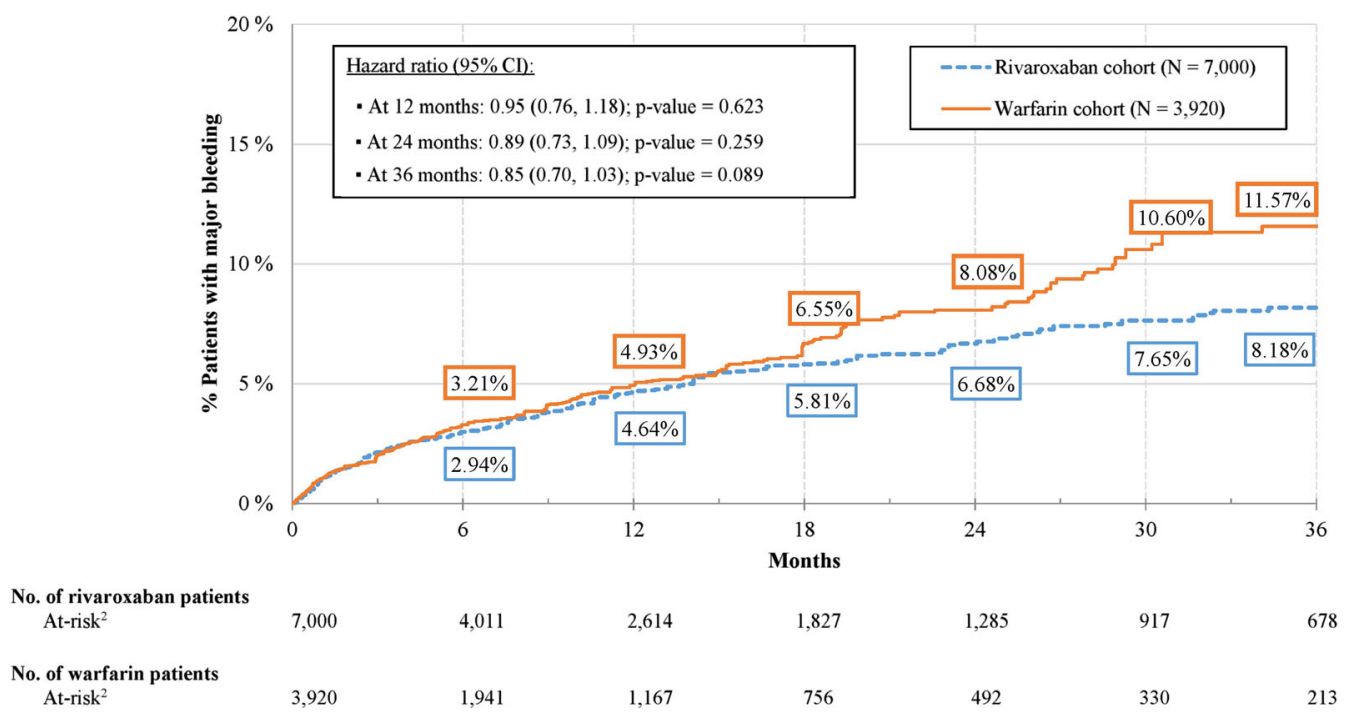

Fig. 3 Kaplan-Meier rates of major bleeding: NVAF patients with obesity and polypharmacy ( $\geq 5$ medications) - rivaroxaban vs. warfarin (on-treatment analysis). CI confidence interval. Notes: (1) Major bleeding was defined using the Cunningham algorithm, which identifies

significantly lower risk of stroke/SE compared to warfarin at all time points post-index (Table 3). At 36 months of follow-up, patients with 5-9 medications initiated on rivaroxaban had a $31 \%$ lower risk of stroke/SE compared to those initiated on warfarin at 36 months (HR $0.69,95 \%$ CI $0.52,0.92, p=0.011)$, Table 3 ). In the subgroup analysis of patients with $\geq 10$ medications, the risk of stroke/SE was numerically in favor of rivaroxaban- compared to warfarin-treated patients at all time points post-index; however, these differences did not attain statistical significance, which may reflect a lack of power due to low sample sizes (Table 3). Stroke (i.e., ischemic stroke and hemorrhagic stroke) and hemorrhagic stroke outcomes are reported in Table S7.

In the subgroup with 5-9 medications, the risk of major bleeding was significantly lower among rivaroxaban-treated patients at 36 months of follow-up (HR 0.75, 95\% CI 0.58, $0.96, p=0.023)$. Risk of major bleeding was numerically but not significantly lower in rivaroxaban- compared to warfarin-treated patients at 12 months (HR 0.82, 95\% CI 0.62, $1.10, p=0.184$ ) and 24 months (HR 0.78, 95\% hospitalizations with diagnoses and procedures indicating an episode of bleeding (excluding bleeding due to major trauma). (2) Number of patients still observed at the specific point in time

CI $0.60,1.01, p=0.062$; Table 4). In the subgroup with $\geq 10$ medications, the risk of major bleeding was comparable between rivaroxabanand warfarin-treated patients (Table 4).

\section{DISCUSSION}

This retrospective weighted-cohort study evaluated the comparative effectiveness and safety of rivaroxaban and warfarin among NVAF patients with obesity and polypharmacy in the US population. Rivaroxaban was associated with a significantly lower risk of stroke/SE in this population at 36 months of follow-up, whereas risk of major bleeding was numerically but not significantly lower compared to warfarin. Subgroup analyses stratified by polypharmacy level (5-9 or $\geq 10$ medications) yielded results that were largely consistent with the overall polypharmacy analysis. The present findings support our initial hypothesis that rivaroxaban is a viable treatment option among complex NVAF patients with obesity and polypharmacy and shows long-term incremental benefits when compared to warfarin. A further strength of the present study is its focus on a 
Table 3 Time to first stroke/SE: NVAF patients with obesity and polypharmacy stratified by polypharmacy subgrouprivaroxaban vs. warfarin (intention-to-treat analysis)

\begin{tabular}{|c|c|c|c|c|c|}
\hline \multicolumn{2}{|c|}{$\begin{array}{l}\text { Time to first stroke/SE } \\
\text { (Time period after the index date) }\end{array}$} & \multicolumn{2}{|c|}{$\begin{array}{l}\text { (Kaplan-Meier estimates) } \\
\text { Survival function }\end{array}$} & \multirow[t]{2}{*}{ HR $(95 \% \mathrm{CI})^{\mathrm{b}}$} & \multirow[t]{2}{*}{$p$ value $^{\mathrm{b}}$} \\
\hline & & Rivaroxaban & Warfarin & & \\
\hline \multirow[t]{6}{*}{ 5-9 Medications } & Number of patients, $n$ & 5339 & 2574 & & \\
\hline & $\begin{array}{c}\text { Observation period, }{ }^{\mathrm{c}} \text { months, } \\
\text { mean } \pm \mathrm{SD}[\text { median }]\end{array}$ & $20.4 \pm 12.9[19]$ & $19.7 \pm 13.0[18]$ & & \\
\hline & Stroke/SE (months) & & & & \\
\hline & 12 & $1.59 \%$ & $2.50 \%$ & $0.63(0.44,0.89)$ & 0.009 \\
\hline & 24 & $2.41 \%$ & $3.84 \%$ & $0.62(0.46,0.85)$ & 0.003 \\
\hline & 36 & $3.42 \%$ & $4.44 \%$ & $0.69(0.52,0.92)$ & 0.011 \\
\hline \multirow[t]{6}{*}{$\geq 10$ Medications } & Number of patients, $n$ & 1661 & 1346 & & \\
\hline & $\begin{array}{l}\text { Observation period, }{ }^{c} \text { months, } \\
\text { mean } \pm \text { SD }[\text { median }]\end{array}$ & $19.8 \pm 13.0[18]$ & $19.2 \pm 12.8[17]$ & & \\
\hline & Stroke/SE (months) & & & & \\
\hline & 12 & $2.31 \%$ & $2.71 \%$ & $0.78(0.48,1.25)$ & 0.301 \\
\hline & 24 & $3.47 \%$ & $4.46 \%$ & $0.78(0.52,1.17)$ & 0.230 \\
\hline & 36 & $4.16 \%$ & $6.33 \%$ & $0.78(0.54,1.14)$ & 0.207 \\
\hline
\end{tabular}

$C I$ confidence interval, $H R$ hazard ratio, $S E$ systemic embolism, $S D$ standard deviation

${ }^{a}$ Defined as a primary diagnosis of ischemic stroke, hemorrhagic stroke, or SE during a hospitalization or emergency room visit

${ }^{\mathrm{b}}$ Calculated using Cox proportional hazards models

c The observation period spans from the index date until the earliest of 36 months, health plan disenrollment, or end of data availability

commercially-insured cohort of younger patients who are distinct from the general AF population but significantly impacted by obesity as a risk factor [13].

The current study expands upon previous research regarding the impact of anticoagulants among NVAF patients with obesity. Prior evidence has suggested that rivaroxaban and warfarin have comparable safety and effectiveness among NVAF patients with obesity $[25,27,29,31]$. However, more recent findings indicate that rivaroxaban may be more effective compared to warfarin in this population $[28,30]$. In a study by the present authors evaluating patients with NVAF and obesity [30], rivaroxaban was associated with a $26 \%$ lower risk of stroke/SE (HR 0.74, 95\% CI 0.60, 0.91) with no significant difference in the risk of major bleeding compared to warfarin (HR 0.85, 95\% CI 0.71, 1.02). The current study corroborates these findings, suggesting that rivaroxaban remains safe and effective in this population despite the use of multiple concurrent medications. Costa et al.[28] analyzed electronic health record data of NVAF patients with obesity and found that rivaroxaban-treated patients had a $17 \%$ and $18 \%$ lower risk of stroke/SE (HR 0.83, 95\% CI 0.73, 0.94) and major bleeding (HR $0.82,95 \%$ CI $0.75,0.89)$ compared with warfarin-treated patients, respectively. Consistent with this, rivaroxaban was associated with a significantly lower risk of stroke/SE and major bleeding in the subgroup with 5-9 medications in the present study. 
Table 4 Time to first major bleeding: NVAF patients with obesity and polypharmacy stratified by polypharmacy subgroup-rivaroxaban vs. warfarin (on-treatment analysis)

\begin{tabular}{|c|c|c|c|c|c|}
\hline \multicolumn{2}{|c|}{$\begin{array}{l}\text { Time to first major bleeding } \\
\text { (Time period after the index date) }\end{array}$} & \multicolumn{2}{|c|}{$\begin{array}{l}\text { (Kaplan-Meier estimates) } \\
\text { Survival function }\end{array}$} & \multirow[t]{2}{*}{ HR $(95 \% \mathrm{CI})^{\mathrm{b}}$} & \multirow[t]{2}{*}{$p$ value $\mathrm{b}^{\mathrm{b}}$} \\
\hline & & Rivaroxaban & Warfarin & & \\
\hline \multirow[t]{6}{*}{ 5-9 Medications } & Number of patients, $n$ & 5339 & 2574 & & \\
\hline & $\begin{array}{l}\text { Observation period, }{ }^{\mathrm{c}} \text { months, } \\
\text { mean } \pm \mathrm{SD}[\text { median }]\end{array}$ & $12.7 \pm 11.8[8]$ & $10.2 \pm 10.7[6]$ & & \\
\hline & Major bleeding (months) & & & & \\
\hline & 12 & $3.66 \%$ & $4.27 \%$ & $0.82(0.62,1.10)$ & 0.184 \\
\hline & 24 & $5.16 \%$ & $6.98 \%$ & $0.78(0.60,1.01)$ & 0.062 \\
\hline & 36 & $6.41 \%$ & $10.18 \%$ & $0.75(0.58,0.96)$ & 0.023 \\
\hline \multirow[t]{6}{*}{$\geq 10$ Medications } & Number of patients, $n$ & 1661 & 1346 & & \\
\hline & $\begin{array}{l}\text { Observation period, }{ }^{\mathrm{c}} \text { months, } \\
\text { mean } \pm \mathrm{SD}[\text { median }]\end{array}$ & $11.9 \pm 11.6[7]$ & $10.2 \pm 10.4[6]$ & & \\
\hline & Major bleeding (months) & & & & \\
\hline & 12 & $7.19 \%$ & $6.77 \%$ & $1.12(0.80,1.58)$ & 0.499 \\
\hline & 24 & $10.76 \%$ & $10.96 \%$ & $1.06(0.78,1.44)$ & 0.713 \\
\hline & 36 & $12.71 \%$ & $15.37 \%$ & $0.99(0.73,1.33)$ & 0.929 \\
\hline
\end{tabular}

$C I$ confidence interval, $H R$ hazard ratio, $S D$ standard deviation

${ }^{a}$ Major bleeding was identified with the Cunningham algorithm, which identifies hospitalizations with diagnoses and procedures indicating an episode of bleeding (excluding bleeding due to major trauma)

${ }^{\mathrm{b}}$ Calculated using Cox proportional hazards models

$c$ The observation period spans from the index date until the earliest date of discontinuation (defined as the earliest of a gap in days of supply [i.e., $\geq 60$ days] between the end of a dispensing [based on days of supply] and the next fill or between the end of the last dispensing and the end of data), switch to or addition of another oral anticoagulant, 36 months, health plan disenrollment, or end of data availability

The present findings also add to a growing body of evidence showing that rivaroxaban is safe and effective across complex patients with polypharmacy, irrespective of body weight $[37,44,46]$. In an analysis of the ROCKET AF clinical trial population by Piccini et al. [44], there was no difference in stroke and bleeding outcomes between rivaroxaban- and warfarintreated patients according to the number of concurrent medications, particularly among those with higher polypharmacy use (i.e., 5-9 and $\geq 10$ medications). In the superiority analysis of the ROCKET AF trial population by Patel et al. [27], rivaroxaban had a similar efficacy profile in reducing stroke/SE with a lower risk of intracranial hemorrhage compared to warfarin, whereas the present study observed lower rates of stroke/SE and comparable rates of major bleeding with rivaroxaban. In the present study, hemorrhagic stroke was included in the definition of a major bleeding event and also comprised intracranial hemorrhage. The results of our analysis show that risk of hemorrhagic stroke was significantly reduced among patients treated with rivaroxaban compared to those treated with warfarin. Differences between the 
present study findings and those obtained in the ROCKET AF trial population may partly reflect distinct patient characteristics, since the latter population was of older age (median 73 years) with normal BMI (median $\sim 28 \mathrm{~kg} /$ $\mathrm{m}^{2}$ ) $[27,44]$. While the present study included patients with a broad range of risk for stroke/SE, the ROCKET AF trial selected for patients with moderate-to-high risk of stroke, $90 \%$ of whom were required to have had a previous ischemic stroke, transient ischemic attack, or SE and two or more risk factors $[27,44]$.

Subsequent observational studies, including the present study, further suggest that rivaroxaban is a safe and effective option among patients with polypharmacy $[37,46]$. In a recent retrospective study by Mentias et al. [46], the comparative effectiveness and safety of oral anticoagulants was evaluated in Medicare patients aged $\geq 65$ with low, moderate, or high polypharmacy (i.e., $\leq 3,4-8$, or $\geq 9$ other prescription medications, respectively). Overall, the risk of ischemic stroke and bleeding was similar for rivaroxaban compared to warfarin across polypharmacy levels [46]. A retrospective study by Martinez et al.[37] evaluated the safety and effectiveness of rivaroxaban and warfarin among polypharmacy users $(\geq 5$ or $\geq 10$ medications) based on a data source encompassing a mix of commercial, Medicare, and Medicaid insurance plans. Consistent with the present study, rivaroxaban was associated with a significantly lower risk of stroke/SE among patients with $\geq 5$ medications, while the difference did not attain statistical significance for patients with $\geq 10$ medications. Rivaroxaban and warfarin were associated with a similar risk of major bleeding in both polypharmacy subgroups in this study [37].

The present study findings are clinically relevant for several reasons. First, the high polypharmacy burden associated with NVAF may translate into poor clinical outcomes [51], including an increased risk of major bleeding $[34,44]$. Second, the most common multi-drug combinations in the US are for comorbidities and complications related to obesity, including cardiometablic syndrome $[36,38]$. Taken together, NVAF patients with obesity and polypharmacy represent a population with a particularly high unmet need for safe and effective treatments. In the present study, the use of multiple medications did not appear to compromise the safety and effectiveness of rivaroxaban in this population. Given the challenges associated with managing complex patients with multimorbidity and polypharmacy [51], these findings may help to inform future treatment decisions. Although polypharmacy is highly prevalent among elderly patients with AF [34], recent evidence suggests that it may increase the risk of adverse clinical outcomes independent of age [52]. Nonetheless, the majority of prior studies evaluating clinical outcomes among rivaroxaban and warfarin users with polypharmacy relied on data from older populations (i.e., median $\geq 70$ years) $[37,44,46]$. The present study thus builds on these previous findings by documenting the benefits of rivaroxaban in relatively young patients with commercial insurance plans.

The present study should be viewed in the context of certain limitations. Obesity was classified based on ICD diagnosis codes for high BMI and not a patient's actual BMI value. Since height and weight are not available in claims data, it is possible that some patients with obesity were not captured in this analysis. Previous validation studies have shown that diagnostic obesity codes may underestimate the true prevalence of obesity. However, given the high specificity and modest to high PPV, obese patients can be identified using diagnosis codes $[47,53-55]$. The present study may have been subject to additional limitations commonly associated with retrospective claims analyses, including coding inaccuracies that may lead to misidentification and the lack of availability of certain prescription-related information (i.e., medications administered in inpatient settings and over-the-counter medications). Despite the use of IPTW, the present study results may have also been influenced by unmeasured confounders not available in claims databases. Finally, the present study population was broadly representative of patients with commercial insurance in the US; therefore, the results may not be generalizable to other populations. 


\section{CONCLUSION}

In this real-world study of NVAF patients with obesity and polypharmacy in the US, rivaroxaban was associated with a significantly lower risk of stroke/SE and a similar risk of major bleeding compared to warfarin over a 36-month follow-up period. This pattern of results remained consistent in the subgroup analyses of patients with 5-9 and $\geq 10$ medications. Overall, the present findings suggest that rivaroxaban is a safe and effective treatment with longterm benefits compared to warfarin among complex NVAF patients with obesity and polypharmacy in a commercially-insured US population.

\section{ACKNOWLEDGEMENTS}

Funding. The present study and the journal's Rapid Service fee were funded by Janssen Scientific Affairs, LLC.

Author Contributions. Jeffrey S. Berger, Veronica Ashton, Akshay Kharat, and Kenneth Todd Moore made substantial contributions to the conception of the present study. All authors made substantial contributions to data curation and study design. François Laliberté, Dominique Lejeune, Young Jung, and Patrick Lefebvre contributed to the formal analysis. All authors contributed to the drafting of the completed work or revised it critically for important intellectual content.

Authorship. All named authors meet the International Committee of Medical Journal Editors (ICMJE) criteria for authorship for this article, take responsibility for the integrity of the work as a whole, and have given their approval for this version to be published.

Medical Writing Assistance. Medical writing assistance was provided by Mona Lisa Chanda, PhD, an employee at Analysis Group, Inc. This assistance was funded by Janssen Scientific Affairs, LLC.
Disclosures. Jeffrey S. Berger received consultancy fees from Janssen Scientific Affairs, LLC. Veronica Ashton and Akshay Kharat are employees of Janssen Scientific Affairs, LLC, and Kenneth Todd Moore is an employee at Janssen Pharmaceuticals Inc. who may own stock or stock options. François Laliberté, Dominique Lejeune, Young Jung, and Patrick Lefebvre are employees of Analysis Group, Inc., a consulting firm that received consulting fees from Janssen Scientific Affairs, LLC, for the conduct of this study.

Compliance with Ethics Guidelines. All database records were statistically de-identified and certified as fully compliant with US patient confidentiality requirements outlined in the Health Insurance Portability and Accountability Act. Permission to access these records for the current study was granted by IQVIA PharMetrics ${ }^{\circledR}$ Plus data. Because the current study relied exclusively on de-identified patient records and did not involve the collection, use, or dissemination of individually identifiable data, institutional review board approval was not necessary.

Data Availability. The data that support the findings of this study are available from IQVIA PharMetrics ${ }^{\circledR}$ Plus data but restrictions apply to the availability of these data, which were used under license for the current study, and so are not publicly available.

Open Access. This article is licensed under a Creative Commons Attribution-NonCommercial 4.0 International License, which permits any non-commercial use, sharing, adaptation, distribution and reproduction in any medium or format, as long as you give appropriate credit to the original author(s) and the source, provide a link to the Creative Commons licence, and indicate if changes were made. The images or other third party material in this article are included in the article's Creative Commons licence, unless indicated otherwise in a credit line to the material. If material is not included in the article's Creative Commons licence and your intended use is not permitted by statutory regulation or exceeds the permitted use, you 
will need to obtain permission directly from the copyright holder. To view a copy of this licence, visit http://creativecommons.org/licenses/by$\mathrm{nc} / 4.0 /$.

\section{REFERENCES}

1. Wong CX, Sullivan T, Sun MT, Mahajan R, Pathak RK, Middeldorp M, et al. Obesity and the risk of incident, post-operative, and post-ablation atrial fibrillation: a meta-analysis of 626,603 individuals in 51 studies. JACC Clin Electrophysiol. 2015;1(3): 139-52.

2. Wang TJ, Parise H, Levy D, D'Agostino RB Sr, Wolf PA, Vasan RS, et al. Obesity and the risk of newonset atrial fibrillation. JAMA. 2004;292(20): 2471-7.

3. Wolf PA, Abbott RD, Kannel WB. Atrial fibrillation as an independent risk factor for stroke: the Framingham Study. Stroke. 1991;22(8):983-8.

4. Lim GB. Atrial fibrillation. Risk of systemic emboli in AF. Nat Rev Cardiol. 2015;12(10):561.

5. Feinberg WM, Blackshear JL, Laupacis A, Kronmal R, Hart RG. Prevalence, age distribution, and gender of patients with atrial fibrillation. Analysis and implications. Arch Intern Med. 1995;155(5): 469-73.

6. Khairallah F, Ezzedine R, Ganz LI, London B, Saba S. Epidemiology and determinants of outcome of admissions for atrial fibrillation in the United States from 1996 to 2001. Am J Cardiol. 2004;94(4):500-4.

7. Lane DA, Skjoth F, Lip GYH, Larsen TB, Kotecha D. Temporal trends in incidence, prevalence, and mortality of atrial fibrillation in primary care. J Am Heart Assoc. 2017. https://doi.org/10.1161/JAHA. 116.005155.

8. Miyasaka Y, Barnes ME, Gersh BJ, Cha SS, Bailey KR, Abhayaratna WP, et al. Secular trends in incidence of atrial fibrillation in Olmsted County, Minnesota, 1980 to 2000 , and implications on the projections for future prevalence. Circulation. 2006;114(2): 119-25.

9. Berkovitch A, Kivity S, Klempfner R, Segev S, Milwidsky A, Erez A, et al. Body mass index and the risk of new-onset atrial fibrillation in middle-aged adults. Am Heart J. 2016;173:41-8.

10. Schmidt M, Botker HE, Pedersen L, Sorensen HT. Comparison of the frequency of atrial fibrillation in young obese versus young nonobese men undergoing examination for fitness for military service. Am J Cardiol. 2014;113(5):822-6.

11. Karasoy D, Bo Jensen T, Hansen ML, Schmiegelow M, Lamberts M, Gislason GH, et al. Obesity is a risk factor for atrial fibrillation among fertile young women: a nationwide cohort study. Europace. 2013;15(6):781-6.

12. Tedrow UB, Conen D, Ridker PM, Cook NR, Koplan BA, Manson JE, et al. The long- and short-term impact of elevated body mass index on the risk of new atrial fibrillation the WHS (women's health study). J Am Coll Cardiol. 2010;55(21):2319-27.

13. Foy AJ, Mandrola J, Liu G, Naccarelli GV. Relation of obesity to new-onset atrial fibrillation and atrial flutter in adults. Am J Cardiol. 2018;121(9):1072-5.

14. Reiffel JA. Atrial fibrillation and stroke: epidemiology. Am J Med. 2014;127(4):e15-6.

15. U.S. Food and Drug Administration. ELIQUIS (apixaban)-Labeling-Patient Package Insert Accessed on: Sep 9. https://www.accessdata.fda.gov/ drugsatfda_docs/label/2012/202155s000lbl.pdf.

16. U.S. Food and Drug Administration. PRADAXA ${ }^{\circledR}$ (dabigatran etexilate) - Labeling-Patient Package Insert Accessed on: Sep 9. https://www.accessdata. fda.gov/drugsatfda_docs/label/2020/ 022512s039lbl.pdf.

17. U.S. Food and Drug Administration. XARELTO ${ }^{\circledR}$ (rivaroxaban) -Labeling-Patient Package Insert Accessed on: Sep 9. https://www.accessdata.fda. gov/drugsatfda_docs/label/2020/ 202439s031,022406s035lbl.pdf.

18. Saraiva JFK. Stroke prevention with oral anticoagulants: summary of the evidence and efficacy measures as an aid to treatment choices. Cardiol Ther. 2018;7(1):15-24.

19. Dzeshka MS, Lip GY. Non-vitamin K oral anticoagulants in atrial fibrillation: Where are we now? Trends Cardiovasc Med. 2015;25(4):315-36.

20. Kirchhof P, Benussi S, Kotecha D, Ahlsson A, Atar D, Casadei B, et al. 2016 ESC Guidelines for the management of atrial fibrillation developed in collaboration with EACTS. Eur J Cardiothorac Surg. 2016;50(5):e1-88.

21. Compendium EM. SPC. Warfarin $0.5 \mathrm{mg}$ tablets. Accessed on: Nov 22. https://www.medicines.org. uk/emc/medicine/27651.

22. Kubitza D, Becka M, Zuehlsdorf M, Mueck W. Body weight has limited influence on the safety, tolerability, pharmacokinetics, or pharmacodynamics of 
rivaroxaban (BAY 59-7939) in healthy subjects. J Clin Pharmacol. 2007;47(2):218-26.

23. Willmann S, Zhang L, Frede M, Kubitza D, Mueck W, Schmidt S, et al. Integrated population pharmacokinetic analysis of rivaroxaban across multiple patient populations. CPT Pharmacometrics Syst Pharmacol. 2018;7(5):309-20.

24. Barsam SJ, Patel JP, Roberts LN, Kavarthapu V, Patel RK, Green B, et al. The impact of body weight on rivaroxaban pharmacokinetics. Res Pract Thromb Haemost. 2017;1(2):180-7.

25. Balla SR, Cyr DD, Lokhnygina Y, Becker RC, Berkowitz SD, Breithardt G, et al. Relation of risk of stroke in patients with atrial fibrillation to body mass index (from patients treated with rivaroxaban and warfarin in the rivaroxaban once daily oral direct factor $\mathrm{Xa}$ inhibition compared with vitamin $\mathrm{K}$ antagonism for prevention of stroke and embolism trial in atrial fibrillation trial). Am J Cardiol. 2017;119(12):1989-96.

26. Martin K, Beyer-Westendorf J, Davidson BL, Huisman MV, Sandset PM, Moll S. Use of the direct oral anticoagulants in obese patients: guidance from the SSC of the ISTH. J Thrombosis Haemostasis. 2016;14(6):1308-13.

27. Patel MR, Mahaffey KW, Garg J, Pan G, Singer DE, Hacke W, et al. Rivaroxaban versus warfarin in nonvalvular atrial fibrillation. $\mathrm{N}$ Engl $\mathrm{J}$ Med. 2011;365(10):883-91.

28. Costa OS, Beyer-Westendorf J, Ashton V, Milentijevic D, Moore KT, Bunz TJ, et al. Effectiveness and safety of rivaroxaban versus warfarin in obese nonvalvular atrial fibrillation patients: analysis of electronic health record data. Curr Med Res Opin. 2020;36(7):1081-8.

29. Peterson ED, Ashton V, Chen YW, Wu B, Spyropoulos AC. Comparative effectiveness, safety, and costs of rivaroxaban and warfarin among morbidly obese patients with atrial fibrillation. Am Heart J. 2019;212:113-9.

30. Berger JS, Laliberté F, Kharat A, Lejeune D, Moore $\mathrm{KT}$, Jung Y, et al. Real-world effectiveness and safety of Rivaroxaban versus Warfarin among non-valvular atrial fibrillation patients with obesity in a US population. Curr Med Res Opin. 2021; 1-1.

31. Kido K, Ngorsuraches S. Comparing the efficacy and safety of direct oral anticoagulants with warfarin in the morbidly obese population with atrial fibrillation. Ann Pharmacother. 2019;53(2):165-70.

32. Kushnir M, Choi Y, Eisenberg R, Rao D, Tolu S, Gao J, et al. Efficacy and safety of direct oral factor Xa inhibitors compared with warfarin in patients with morbid obesity: a single-centre, retrospective analysis of chart data. Lancet Haematol. 2019;6(7): e359-65.

33. Gnjidic D, Hilmer SN, Blyth FM, Naganathan V, Waite L, Seibel MJ, et al. Polypharmacy cutoff and outcomes: five or more medicines were used to identify community-dwelling older men at risk of different adverse outcomes. J Clin Epidemiol. 2012;65(9):989-95.

34. Chen N, Alam AB, Lutsey PL, MacLehose RF, Claxton JS, Chen LY, et al. Polypharmacy, adverse outcomes, and treatment effectiveness in patients $>/=$ 75 with atrial fibrillation. J Am Heart Assoc. 2020;9(11):e015089.

35. Masnoon N, Shakib S, Kalisch-Ellett L, Caughey GE. What is polypharmacy? A systematic review of definitions. BMC Geriatr. 2017;17(1):230.

36. Kantor ED, Rehm CD, Haas JS, Chan AT, Giovannucci EL. Trends in prescription drug use among adults in the United States from 1999-2012. JAMA. 2015;314(17):1818-30.

37. Martinez BK, Baker WL, Sood NA, Bunz TJ, Meinecke AK, Eriksson D, et al. Influence of polypharmacy on the effectiveness and safety of Rivaroxaban versus Warfarin in patients with nonvalvular atrial fibrillation. Pharmacotherapy. 2019;39(2):196-203.

38. Quinn KJ, Shah NH. A dataset quantifying polypharmacy in the United States. Scientific data. 2017;4:170167.

39. Assari S, Wisseh C, Bazargan M. Obesity and polypharmacy among African American older adults: gender as the moderator and multimorbidity as the mediator. Int J Environ Res Public Health. 2019;16(12):2181.

40. Rose AJ, Hylek EM, Ozonoff A, Ash AS, Reisman JI, Berlowitz DR. Patient characteristics associated with oral anticoagulation control: results of the Veterans AffaiRs Study to Improve Anticoagulation (VARIA). J Thrombosis Haemostasis. 2010;8(10):2182-91.

41. Mohammed S, Aljundi AH, Kasem M, Alhashemi M, El-Menyar A. Anticoagulation control among patients with nonvalvular atrial fibrillation: a single tertiary cardiac center experience. J Adv Pharm Technol Res. 2017;8(1):14-8.

42. Eggebrecht L, Nagler M, Gobel S, Lamparter $H$, Keller K, Wagner B, et al. Relevance of polypharmacy for clinical outcome in patients receiving Vitamin $\mathrm{K}$ antagonists. J Am Geriatr Soc. 2019;67(3):463-70. 
43. Harskamp RE, Teichert M, Lucassen WAM, van Weert H, Lopes RD. Impact of polypharmacy and P-glycoprotein- and CYP3A4-modulating drugs on safety and efficacy of oral anticoagulation therapy in patients with atrial fibrillation. Cardiovasc Drugs Ther. 2019;33(5):615-23.

44. Piccini JP, Hellkamp AS, Washam JB, Becker RC, Breithardt G, Berkowitz SD, et al. Polypharmacy and the efficacy and safety of Rivaroxaban versus Warfarin in the prevention of stroke in patients with nonvalvular atrial fibrillation. Circulation. 2016;133(4):352-60.

45. Teklay G, Shiferaw N, Legesse B, Bekele ML. Drug-drug interactions and risk of bleeding among inpatients on warfarin therapy: a prospective observational study. Thromb J. 2014;12:20.

46. Mentias A, Heller E, Vaughan SM. Comparative effectiveness of rivaroxaban, apixaban, and warfarin in atrial fibrillation patients with polypharmacy. Stroke. 2020;51(7):2076-86.

47. Jain R, Watzker A, Luo X, Kang AL, Baker CL, Rosenblatt L, et al. Validation of obesity coding among newly treated nonvalvular atrial fibrillation patients using an integrated electronic medical record and claims database. Curr Med Res Opin. 2019;40(1):1-9.

48. Cunningham A, Stein CM, Chung CP, Daugherty JR, Smalley WE, Ray WA. An automated database case definition for serious bleeding related to oral anticoagulant use. Pharmacoepidemiol Drug Saf. 2011;20(6):560-6.
49. Austin PC, Stuart EA. Moving towards best practice when using inverse probability of treatment weighting (IPTW) using the propensity score to estimate causal treatment effects in observational studies. Stat Med. 2015;34(28):3661-79.

50. Austin PC. Using the standardized difference to compare the prevalence of a binary variable between two groups in observational research. Commun Stat- Simul Comput. 2009;38(6):1228-34.

51. Shaikh F, Pasch LB, Newton PJ, Bajorek BV, Ferguson $\mathrm{C}$. Addressing multimorbidity and polypharmacy in individuals with atrial fibrillation. Curr Cardiol Rep. 2018;20(5):32.

52. Eggebrecht L, Nagler M, Göbel S, Lamparter H, Keller K, Wagner B, et al. Relevance of polypharmacy for clinical outcome in patients receiving vitamin $\mathrm{K}$ antagonists. $\mathrm{J}$ Am Geriatr Soc. 2019;67(3):463-70.

53. Martin BJ, Chen G, Graham M, Quan H. Coding of obesity in administrative hospital discharge abstract data: accuracy and impact for future research studies. BMC Health Serv Res. 2014;14:70.

54. Lloyd JT, Blackwell SA, Wei II, Howell BL, Shrank WH. Validity of a claims-based diagnosis of obesity among medicare beneficiaries. Eval Health Prof. 2015;38(4):508-17.

55. Ammann EM, Kalsekar I, Yoo A, Johnston SS. Validation of body mass index (BMI)-related ICD-9-CM and ICD-10-CM administrative diagnosis codes recorded in US claims data. Pharmacoepidemiol Drug Saf. 2018;27(10):1092-100. 